\title{
Enterobius vermicularis infection in uterine cavity mimicking endometrial cancer: a case report
}

\author{
Yucel Karaman • Banu Bingol • Ziya Gunenc • \\ Onat Akýn
}

Received: 21 August 2006 / Accepted: 9 January 2007 / Published online: 2 February 2007

(C) Springer-Verlag 2007

Keywords Enterobius vermicularis · Laparoscopy ·

Endometrial cancer

\section{Introduction}

Enterobius vermicularis (pinworm) is an intestinal nematode of humans and causes helminthic infection with a worldwide distribution and high prevalence especially in countries with temperate climates. The adult pinworms usually inhabit the cecum and adjacent gut. Gravid females migrate to the rectum and emerge on the perineum at night depositing eggs [1]; they can also migrate into the vagina and invade reproductive systems of women $[2,3]$. The ova and larvae of the pinworm can be observed in cervicovaginal smears and there are several reports in literature describing associated salpingitis, pelvic inflammatory disease, infections of the ovary, endometrium, pelvic abscess, and generalised peritonitis [4-11]. While there have been limited case reports of enterobiasis of the female reproduc-

Y. Karaman · B. Bingol · Z. Gunenc

Department of Obstetrics and Gynecology,

Metropolitan Florence Nightingale Hospital,

Istanbul, Turkey

O. Akýn

Patomed Pathology Laboratory,

Sisli, Istanbul, Turkey

B. Bingol $(\bowtie)$

Hakki Yeten Caddesi, Plaza Number 10,

Besiktas, Istanbul, Turkey

e-mail: banubingol1975@yahoo.com tive system, we describe a case of postmenopausal woman with enterobiasis in the uterine cavity mimicking endometrial cancer.

\section{Case report}

A 49-year-old woman was admitted to our centre with postmenopausal bleeding. Her previous medical history was unremarkable. On admission, the vital findings and vaginal examination were normal. Ultrasound examination revealed a hypertrophic uterus and an $5 \times 3 \mathrm{~cm}$ intrauterine mass which occupied the whole cavity. Myometrium was very thin, with $0.2 \mathrm{~cm}$ width (Figs. 1 and 2). The ultrasound image resembled an early stage endometrial cancer. Preoperative laboratory tests and tumour markers were normal. Dilatation and curettage was planned in the operation room under laparoscopic guidance because of cervical stenosis, high risk of uterine perforation and/or uterine bleeding (Figs. 1 and 2). Laparoscopic hysterectomy, adnexectomy and, if needed, laparoscopic pelvic and/or paraaortic lymphadenectomy procedures were planned in case of malign causes of postmenopausal bleeding.

After general anesthesia, in lithotomic position, the trocars were inserted and cornual occlusion was performed with atraumatic forceps, considering a probability of an endometrial malignancy. Endometrial curettage was performed for frozen section examination revealed necrotic calcified and inflamed endometrium without any signs of malignancy. Laparoscopy assisted vaginal hysterectomy and adnexectomy was performed, and the specimen was submitted for final pathological examination, which revealed signs of inflamation of endometrium with necrotic 


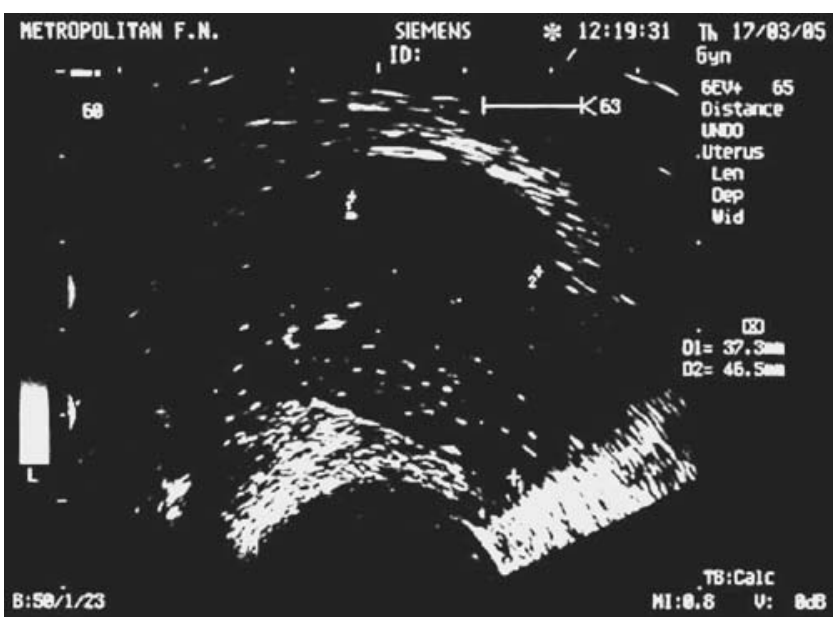

Fig. 1 Ultrasound pictures of Entrobius vermicularis infection in uterus

areas with E. vermicularis type calcified ova (Fig. 3). They measured approximately 20 microns in width, 40 microns in length, were ovoid in shape and had calcified walls (Figs. 4 and 5). The endometrium had chronic inflammation but did not reveal any granulomas, and myometrium was normal. Subsequently, ova of E. vermicularis were found in a stool specimen. The patient was treated with albendazole.

\section{Discussion}

The pinworm, E. vermicularis, is an intestinal parasite of the nematode order, oxyurata, whose name derives from the appearance of its long, thin and pointed tail. The parasite ovum measures 20 microns in width and 40 microns in length, it is ovoid in shape and has a relatively flat surface on one side. The human being is its principal host, and the

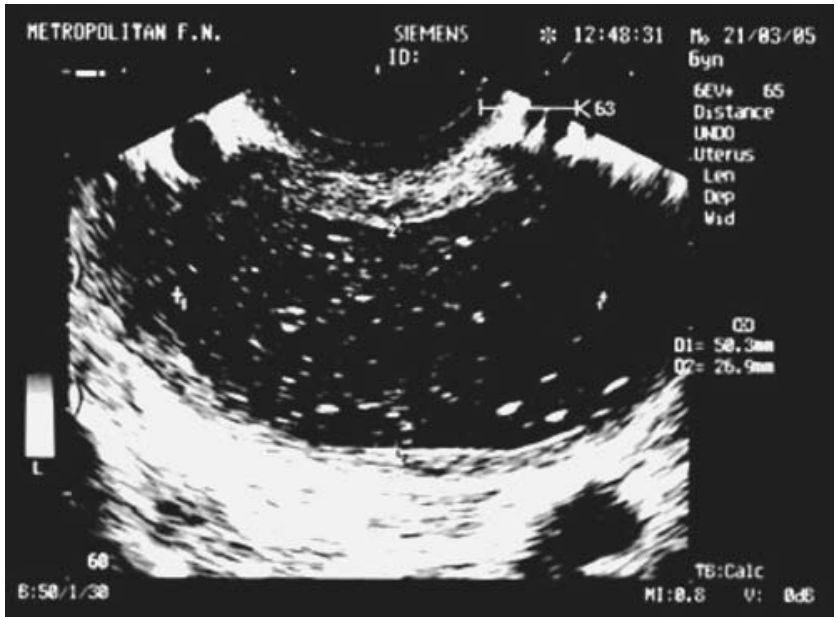

Fig. 2 Ultrasound pictures of Entrobius vermicularis infection in uterus

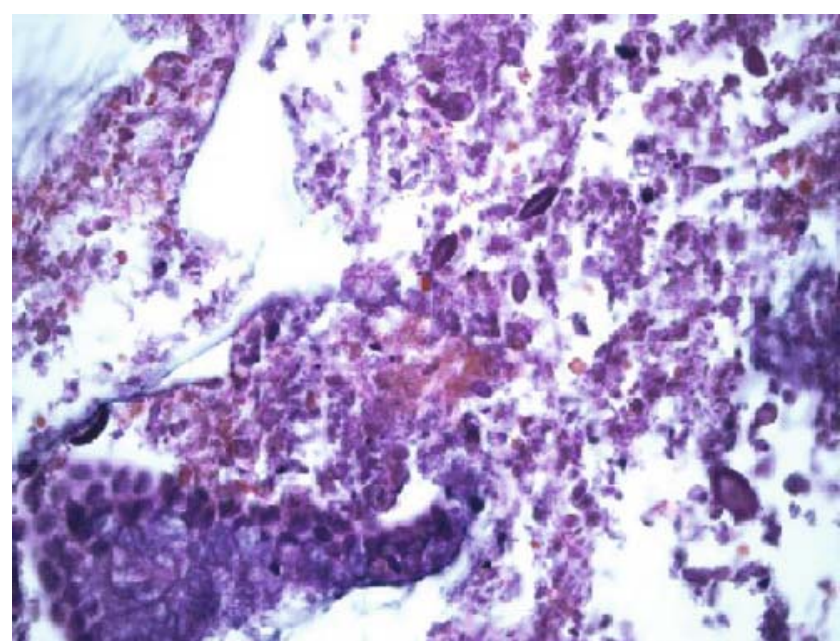

Fig. 3 Enterobius vermicularis ova scattered among endocervical cells

infestation occurs after ingestion of eggs [12]. The embryos hatch in the intestine and inhabit the cecum and adjacent gut, while the gravid migrate to perianal and perineal locations at night. Transmission of infection occurs through fecal-oral route after scratching perineal areas or after handling contaminated fomites [7].

The classic treatment of E.vermicularis infection includes a single dose of pyrantel pamoate, mebendazole or albendazole, repeated after 2 weeks from the initial dose. The treatment must be given to all family members. Experience with mebendazole treatment for extraintestinal enterobiosis is limited. In most of the reported cases patients were treated with mebendazole after surgery [3].

Preoperative diagnosis of extraintestinal enterobiasis is difficult, parasites may be found in cervical smears and vaginal wet mounts $[1,3]$.

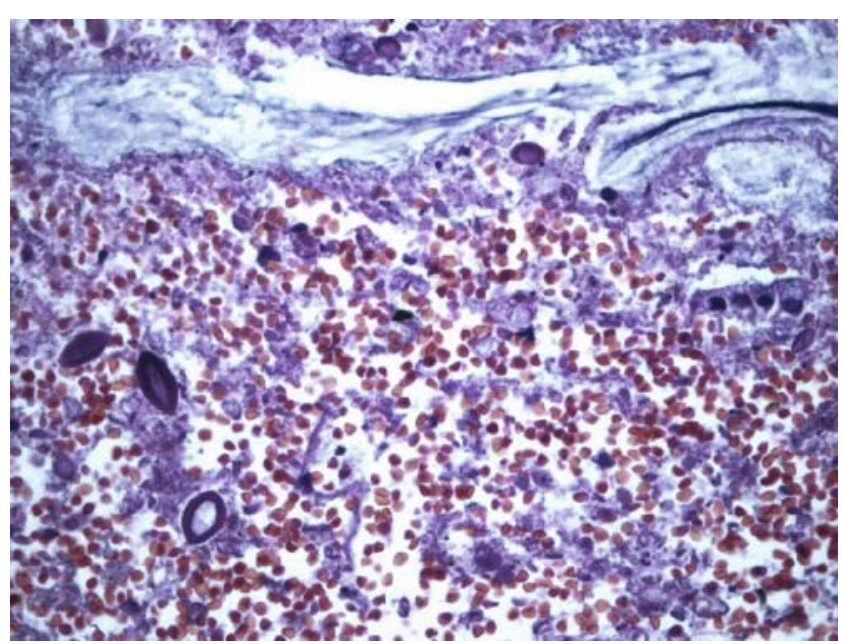

Fig. 4 Multiple Enterobius vermicularis ova 


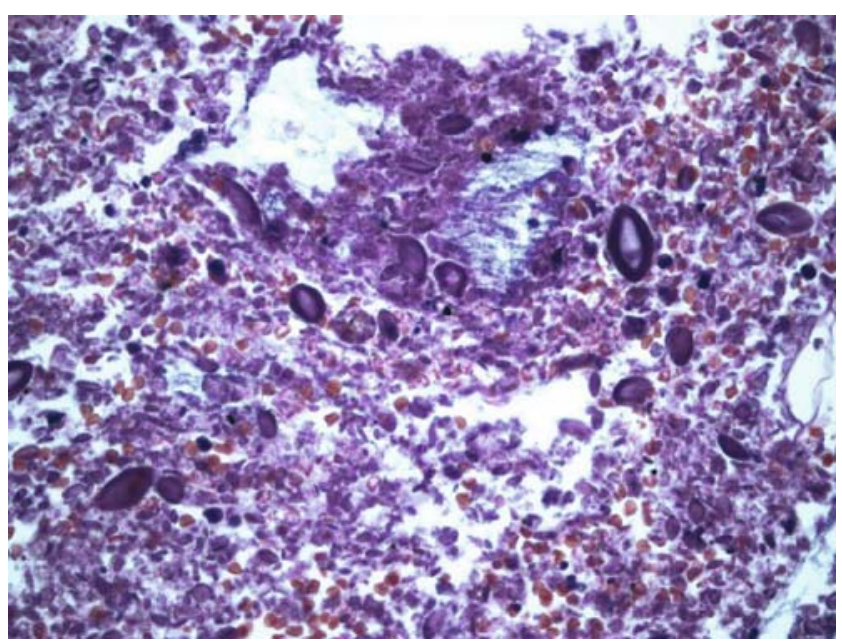

Fig. 5 Multiple Enterobius vermicularis ova

In our case, we think that the patient acquired the infection via her vagina before menopause. During menopausal years, it appears that the cervical canal has been occluded and the infection stayed confined to the endometrial cavity without any apparent symptoms for a while.

There are only three other reported cases of postmenopausal vaginal bleeding associated with pinworms [13]. We report the case because of its ultrasound image resemblence to endometrial carcinoma, its location, unusuality and rare occurrence (Figs. 1 and 2). In addition, we want to emphasise that this pathology can be mistreated with explorative laparotomy and other surgical interventions due to its appearance and clinical behaviour suggesting malignancy.

\section{References}

1. Chung D, Kong HH, Yu HS, Kim J, Cho CR (1997) Live female Enterobius vermicularis in the posterior fornix of the vagina of a Korean woman. Korean J Parasitol 35:67-69

2. Saffos RO, Rhatigan RM (1977) Unilateral salpingitis due to Enterobius vermicularis. Am J Clin Pathol 67:296-299

3. Smolyakov R, Talalay B, Yanai-Inbar I, Pak I, Alkan M (2003) Enterobius vermicularis infection of female genital tract: a report of three cases and review of literature. Eur J Obstet Gynecol Reprod Biol 107:220-222

4. Sizer AR, Nirmal DM, Shannon J, Davies NJ (2004) A pelvic mass due to infestation of the fallopian tube with Enterobius vermicularis. J Obstet Gynecol 24:463

5. Tandan T, Pollard AJ, Money DM, Scheifele DW (2002) Pelvic inflammatory disease associated with Enterobius vermicularis. Arch Dis Child 86:439-440

6. Sobganmu MO (1976) Pelvic inflammatory disease associated with Enterobius vermicularis in the endometrium. East Afr Med J 53:702-706

7. Nabulsi M, Shararah N, Khalil A (1998) Perinatal Enterobius vermicularis infection. Int J Gynaecol Obstet 60:285-286

8. Hong ST, Choi MH, Chai JY, Kim YT, Kim MK, Kim KR (2002) A case of ovarian enterobiasis. Korean J Parasitol 40:149-151

9. Schenken JR, Tamisiea J (1956) Enterobius vermicularis (pinworm) infection of the endometrium; a case report. Am J Obstet Gynecol 72:913-914

10. Das DK, Pahtan SK, Hira PR, Madda JP, Hasaniah WF, Juma TH (2001) Pelvic abscess from Enterobius vermicularis. Report of a case with cytologic detection of eggs and worms. Acta Cytol 45:425-429

11. Khan JS, Steele RJ, Stewart D (1981) Enterobius vermicularis infestation of the female genital tract causing generalised peritonitis. Case report. Br J Obstet Gynaecol 88:681-683

12. Robinson E (2004) Microscopic photography of a pinworm. J Audiov Media Med 27:35-36

13. al-Rufaie HK, Rix GH, Perez Clemente MP, al-Shawaf T (1998) Pinworms and postmenopausal bleeding. J Clin Pathol 51:401-402 